\title{
Using temperature-sensing reticular boluses to aid in the detection of production diseases in dairy cows
}

\author{
A. E. Adams, ${ }^{*}$ F. J. Olea-Popelka, $\dagger$ and I. N. Roman-Muniz ${ }^{* 1}$ \\ ${ }^{*}$ Department of Animal Sciences, College of Agricultural Sciences, and \\ †Department of Clinical Sciences, College of Veterinary Medicine and Biomedical Sciences, Colorado State University, Fort Collins 80523
}

\begin{abstract}
The objective of this study was to investigate associations between increases in reticular temperature (RT) in dairy cows and the diagnosis of metritis, mastitis, lameness, and pneumonia by dairy personnel. A prospective case-control study was conducted on a 2,175-cow dairy operation in Colorado from May 2010 to April 2011. Each cow received an orally administered temperature sensing reticular bolus after parturition and RT measurements were recorded 3 times per day as lactating cows exited the milking parlor. A cow was identified as having an increased RT when a deviation of $0.8^{\circ} \mathrm{C}$ above baseline (average of readings of previous $10 \mathrm{~d}$ ) was recorded by the TempTrack software (DVM Systems, LLC, Greeley, CO). During the same study period, dairy personnel without access to RT data recorded health events and classified them according to clinical signs observed. A total of 201 health events (cases) were included in the data analysis. Cows with clinical mastitis and pneumonia had significantly higher odds (6.7 and 7.5 times higher, respectively) of having an increased RT of $0.8^{\circ} \mathrm{C}$ above their baseline within $4 \mathrm{~d}$ preceding diagnosis when compared with control cows. Specificity and sensitivity for an increase of $0.8^{\circ} \mathrm{C}$ above baseline RT within $4 \mathrm{~d}$ of disease diagnosis was 76.85 and $66.97 \%$ for mastitis, and 69.23 and $76.92 \%$ for pneumonia, respectively. No significant difference in RT was found for cows diagnosed with lameness or metritis. Results of this study suggest that RT monitoring can be a useful tool in the early detection of mastitis and pneumonia in dairy cows.
\end{abstract}

Key words: reticular temperature, dairy cow disease diagnosis

\section{INTRODUCTION}

Body temperature monitoring is a common practice employed on dairy farms as a way of detecting disease

Received June 8, 2012

Accepted November 26, 2012

${ }^{1}$ Corresponding author: inromanm@colostate.edu in dairy cows (Shutz and Bewley, 2009). Nakamura et al. (1983) describe body temperature as the single most useful measurable parameter and a sensitive indicator of the reactions of the animal to physico-environmental factors, disease processes, and physiologic functions such as nutrition, lactation, and reproduction. Many diseases affect dairy cows, including acidosis, metritis, retained fetal membranes, left displaced abomasum, mastitis, pneumonia, hypocalcemia, and lameness (Kelton et al., 1998; Kristula et al., 2001; Aaleseth, 2005); of these diseases, metritis, mastitis, lameness, and pneumonia are those that have been shown to result in an increase of the animal's body temperature above normal (Schutz and Bewley, 2009). All of these diseases may result in economic losses to the dairy producer due to decreased milk yield, increased treatment and veterinary costs, and increased risk of culling (LeBlanc et al., 2002; Juarez et al., 2003; Melendez et al., 2004; Melendez and Risco, 2005; Colak et al., 2008; Bicalho et al., 2009; Cha et al., 2010; Akers and Nickerson, 2011).

Many different techniques are used in the dairy industry to aid in the detection of sick cows. Some of these methods include monitoring daily walking activity, milk yield, rectal temperature, and reticular temperature (RT) (Edwards and Tozer, 2004; Bewley et al., 2008a; Colak et al., 2008; Wenz et al., 2011). Measuring body temperature using a rectal thermometer is the most common method employed on dairy farms to identify and survey sick cows, mainly because of ease of use and low input costs (Hicks et al., 2001; Aalseth, 2005; Burfeind et al., 2010). However, a disadvantage of using rectal temperature to monitor herd health is the manpower required, as the process of measuring the temperature of each cow in a specific pen can be time consuming.

Monitoring cow health by using temperature-sensing reticular boluses (TSRB) is an alternative to rectal temperature monitoring that is easy to use and requires minimal manpower. The TSRB is administered to cows orally using a bolus gun. Once the TSRB has been placed, no other human intervention is needed, as the bolus will reside in the cow's reticulum and provide 
continuous temperature monitoring. Hicks et al. (2001) compared body temperature readings using rectal temperatures to those recorded by ingested and implanted sensors and found no significant difference between the 2 methods. In another study, conducted by Bewley et al. (2008a), RT was found to be strongly correlated with rectal temperature $(\mathrm{r}=0.645)$, with $\mathrm{RT}$ being on average approximately $0.45 \pm 0.33^{\circ} \mathrm{C}$ higher than rectal temperature (Bewley et al., 2008a). Factors that influence RT include ambient temperature, recumbency, stage of gestation, estrus, feed and water intake, and the overall health of the cow (Wrenn et al., 1961; Lefcourt et al., 1999; Bewley et al., 2008b; Schutz and Bewley, 2009); these factors could potentially account for the increased variation found by Bewley et al. (2008a). Although previous studies have examined correlations between rectal and RT, along with the influence of water consumption on RT, more research is needed to assess the value of TSRB in cow health monitoring programs (Bewley et al., 2008a,b). The objective of this pilot study was to investigate associations between increases in RT in cows and the diagnosis of metritis, mastitis, lameness, and pneumonia by dairy personnel. The purpose of the current study was to examine the feasibility of using a TSRB to aid in the early detection of common dairy cow diseases.

\section{MATERIALS AND METHODS}

\section{Cows and Herd Management}

The study examined data collected from May 10, 2010, to April 25, 2011, on a single commercial dairy farm consisting of approximately 2,175 lactating Holstein cows in Colorado. Prior to calving, primiparous and multiparous cows were housed separately in dry lot pens. Dairy employees monitored cows on a daily basis and moved those that appeared close to calving to the fresh pen. After calving, cows were housed in a postpartum pen until their milk was deemed salable (1 to 2 d), at which time they were moved into a fresh pen for approximately 35 d. Primiparous and multiparous cows were housed in separate postpartum pens. Throughout lactation, primiparous and multiparous cows remained separate and were housed in freestall barns, compost barns, or dry lot pens - depending on stage of lactation and reproductive status. Cows were fed a TMR and milked 3 times a day, with a rolling herd average of 30.7 $\mathrm{kg}$ of milk per day throughout the course of the study, without the use of bST hormone.

Cow data were monitored continuously throughout the duration of the study, with 1,047 TSRB being placed over a 350-d period. No devices were lost due to intestinal passage throughout the duration of the study. A total of 705 health events were initially considered for inclusion in the study. These events do not include any case of displaced abomasum, acidosis, retained fetal membranes, or hypocalcemia, because the focus of the study was to investigate associations between fever and diseases previously documented to have pyrexia as a clinical sign. All identical events following the first occurrence of a disease for an individual cow were excluded from this study. Due to the well documented and previously reported wide range in body temperature of otherwise healthy cows during the postpartum period (Kristula et al., 2001; Wagner et al., 2008), health events occurring within the first 7 DIM were excluded to remove the question of whether the temperature deviation of the cow was due to the disease or due to the recent freshening event. Researchers made an exception for cows diagnosed with metritis, as all cases in the current study were diagnosed within the first 12 DIM. Finally, health events were excluded from the analysis if one or more days of RT data were missing from the observational period, resulting in 81 $(11.5 \%)$ health events being removed from the study due to technological problems. In the end, 201 health events were considered in the study, of which 109 were mastitis cases, 64 were lameness, 15 were metritis, and 13 were pneumonia.

\section{Study Design and Definitions}

The experiment was conducted as a prospective casecontrol study. At the time of calving (freshening), each cow in the study received a TSRB (DVM Systems LLC, Greeley, CO), which was administered orally, using a bolus gun, and came to rest in the reticulum of the cow. The bolus measured $95 \mathrm{~mm} \times 23 \mathrm{~mm}$, with a commercial price averaging $\$ 40$ per bolus. As the cow exited the milking parlor she passed a stationary panel reader, which served to power the bolus and obtain a temperature reading of the cow's RT. The RT data were then transferred to the bolus company's TempTrack software (DVM Systems LLC), where it was available for viewing and further analysis. The baseline for individual cows was calculated by averaging the 30 readings from the previous $10 \mathrm{~d}$ (each cow's temperature was read 3 times per day after exiting the milking parlor). Each individual reading was compared with the baseline (all readings that occurred $240 \mathrm{~h}$ before that reading), and each previous reading was then assigned a weight, determined by proprietary algorithms developed by DVM Systems LLC. Readings taken around the same time of day as the reading of interest were emphasized by assigning a higher weight, and readings taken at other times were discounted by assigning a lower weight. Additionally, readings taken near $38.9^{\circ} \mathrm{C}$ 
(the modal temperature across all animals) were also given a higher weight. The result of this processing was a baseline that followed the natural 24-h rhythm of each animal's temperature and was less influenced by unusually high or low temperature variations. The reliability of temperature measurements was engineered to remain stable for the life of the bolus, which exceeds the average life of dairy and beef cattle.

Case Definition. Cases were defined as a cow diagnosed by farm personnel with one of the production diseases in question: mastitis, metritis, lameness, or pneumonia. Cows were monitored daily until 12 DIM by farm personnel, using rectal temperature and rectal palpation to identify fresh cow health disorders. It was during this time period that cows with an elevated rectal temperature reading $\left(>39.5^{\circ} \mathrm{C}\right)$ or an abnormal, foul-smelling, vulvar discharge upon palpation were diagnosed with metritis. Throughout lactation, all cows were monitored by farm personnel for signs of disease according to dairy protocols. Mastitis was diagnosed by the observation of abnormal milk or signs of udder inflammation during foremilk stripping by the milking parlor staff. Cows were observed for signs of lameness daily while walking to and from the milking parlor. Lame cows were diagnosed visually through locomotion scoring, on a scale from 1 to 5 developed by Zinpro (Zinpro-Performance Minerals, Eden Prairie, MN), with 1 being normal and 5 being severely lame. Cows with a locomotion score of 4 or greater were diagnosed as lame. Farm personnel diagnosed cows with pneumonia after performing a physical examination and finding signs of respiratory disease (e.g., increased respiratory rate, nasal discharge, or loud or abnormal respiratory sounds) in conjunction with elevated rectal temperature.

Comparison Group (Controls). In an effort to limit the variability between individual cow baseline RT, mastitis, lameness, and pneumonia, cows were used as their own healthy controls if they had $37 \mathrm{~d}$ with no recorded disease before the week of their health event. Reticular temperature data for the period 31 to $37 \mathrm{~d}$ before the health event were used as healthy controls when examining the data for the $7 \mathrm{~d}$ before the health event; RT for the period 31 to $34 \mathrm{~d}$ before the health event were used as healthy controls when examining the data for the 4-d health event interval. A separate group of controls was selected for comparison purposes for cows diagnosed with metritis, as their diagnosis occurred shortly after calving and no RT data were collected on them before freshening. The control group for metritis consisted of 63 cows (approximately 4 times the number of healthy cows as those diagnosed with a health event), and was chosen using the random number generator in Microsoft Excel 2010 (Microsoft, Redmond, WA) from a group of cows that did not have a health event occur within 17 DIM. This was done to ensure that any temperature change was not influenced by calving.

Exposure Status. A dichotomous variable was created to indicate the presence or absence of an increase in cows' RT. A total of 6 different temperature ranges above a cow's individual baseline were examined, with $0.8^{\circ} \mathrm{C}$ being chosen as an appropriate deviation to indicate a fever when considering specificity and sensitivity. Temperature deviations less than $0.8^{\circ} \mathrm{C}$ produced an excess of false positives, with those above $0.8^{\circ} \mathrm{C}$ producing an excess of false negatives (Table 1 ). When a deviation of $0.8^{\circ} \mathrm{C}\left(1.4^{\circ} \mathrm{F}\right)$ above baseline was observed, a "temperature increase alert" was recorded as 1 (yes), otherwise a 0 was recorded indicating no temperature increase. Increases in RT were evaluated for 2 different timeframes: first the authors assessed associations between core body temperature increases within $7 \mathrm{~d}$ before the health event (and for $7 \mathrm{~d}$ among control cows), and second for a timeframe of $4 \mathrm{~d}$ preceding the health event (and $4 \mathrm{~d}$ among control cows). These timeframes were chosen to ensure that an adequate amount of time elapsed before disease diagnosis to identify any temperature deviations from baseline. For example, although $86 \%$ of mastitis cases had an increased RT within $2 \mathrm{~d}$ before diagnosis, only $65 \%$ of the pneumonia cases had an increased RT during this period, with the remaining $35 \%$ of pneumonia cases having an increased RT on d 3 or 4 before diagnosis. For this reason, the $4-d$ period preceding a health event was chosen as a more acceptable timeframe for inclusion.

Data generated by the TSRB in cows enrolled in the study and gathered by the TempTrack software were not available to the farm personnel during the first 60 DIM. All cows with a health event were identified by farm personnel as showing clinical signs corresponding to the diseases examined in the study. As farm personnel had no knowledge of temperature readings recorded by the TSRB, RT were not used to identify cows with health events.

\section{Data Management}

Data for the date of calving and farm personnelidentified health events were obtained from the on-farm dairy management software (DHI-Plus, DHI Computing Service Inc., Provo, UT). Reticular temperatures were collected using the TSRB and obtained from the bolus company's monitoring software (TempTrack Software).

\section{Statistical Analysis}

All data were entered into a spreadsheet and analyzed using SAS Version 9.3 (SAS Institute Inc., Cary, 
Table 1. Percentage of cows with or without ( + or - , respectively) a reticular temperature (RT) alert and the percentage of cows diagnosed or not (+ or - , respectively) with mastitis or pneumonia, compared for different RT deviations above baseline temperature

\begin{tabular}{lccccc}
\hline $\begin{array}{l}\text { Health } \\
\text { diagnosis }\end{array}$ & $\begin{array}{c}\text { Temperature } \\
\text { deviation }\left({ }^{\circ} \mathrm{C}\right)\end{array}$ & $\begin{array}{c}\text { + Diagnosis }+ \\
\text { RT Alert }(\%)\end{array}$ & $\begin{array}{c}\text { + Diagnosis }- \\
\text { RT Alert }(\%)\end{array}$ & $\begin{array}{c}\text { - Diagnosis }+ \\
\text { RT Alert }(\%)\end{array}$ & $\begin{array}{c}- \text { Diagnosis }- \\
\text { RT Alert }(\%)\end{array}$ \\
\hline Mastitis & 0.6 & 77 & 23 & $53^{2}$ & 23 \\
& 0.8 & 67 & 33 & 10 & 77 \\
Pneumonia & 1.0 & 60 & $40^{1}$ & $39^{2}$ & 31 \\
& 0.6 & 77 & 23 & 69 & 23 \\
\hline
\end{tabular}

${ }^{1}$ Percentage of cows demonstrating an excess of false negatives.

${ }^{2}$ Percentage of cows demonstrating an excess of false positives.

$\mathrm{NC})$. Associations between increases in RT readings by the TSRB and the presence of health-related events were evaluated using PROC FREQ to generate standard cross tabulation $(2 \times 2$ tables $)$. The "exact," "pchi," and "or" statements were used to obtain odd ratios and 95\% confidence intervals with their associated Chi-squared and Fisher's exact test results (when appropriate based on the data distribution) to evaluate associations between health events and RT readings for the 2 timeframes ( 4 and $7 \mathrm{~d}$ ) in this study. Statistical significance was declared at $P<0.05$.

\section{RESULTS AND DISCUSSION}

The associations between increases in RT in cows and the diagnosis of metritis, mastitis, lameness, and pneumonia by dairy personnel are shown in Table 2. Our results indicated that within a 4 -d time frame before the diagnosis of a health event, cows with clinical mastitis had 6.7 times higher odds $(P<0.001)$ of having an increase in RT compared with control cows (same cow in a time frame in which clinical mastitis was not diagnosed). Cows diagnosed with pneumonia had 7.5 times higher odds $(P=0.047)$ of having an increase in RT than cows without pneumonia (Table 2). The majority of cows diagnosed with either mastitis or pneumonia (67 and $77 \%$ respectively) exhibited an increase in RT (greater than $0.8^{\circ} \mathrm{C}$ above their baseline RT), versus only 23 and $31 \%$, respectively, of cows without mastitis and without pneumonia that showed signs of an elevated RT (Table 2). Although the cause of the false positives was not further explored in this study, they could be explained by physiological and environmental factors such as estrus, ambient temperature, and stage of gestation. When examining the 7-d period leading up to diagnosis, mastitis cases had higher odds of having an increase in $\mathrm{RT}$ recorded (odds ratio $=5.0 ; 95 \% \mathrm{CI}=$ 2.7 to $9.4 ; P<0.001)$ compared with the time in which no mastitis was observed. The relationship between cows with pneumonia and controls with temperature increases were identical to that observed in a 4-d period (Table 2).

No difference $(P=0.67)$ was recorded in the number of cows presenting with an increased RT between the cows diagnosed as being lame and those that were not. Only some causes of lameness are known to produce elevated body temperatures, which could explain these findings. Future studies involving a larger experimental group, in which lameness events are classified according to etiology and severity, should provide more information on the potential benefits of RT monitoring in the early diagnosis of lameness in cattle.

Although Sheldon et al. (2006) indicated it is likely that a temperature greater than $39.5^{\circ} \mathrm{C}$ is associated with a cow that has metritis, in this study no difference $(P=0.18)$ was found between the proportion of cows with an increased RT that were diagnosed with metritis and those with no health event. This is supported by others who found that not all cows suffering from metritis have an increase in core temperature (Palenik et al., 2009). In a study conducted by Benzaquen et al. (2007), 58.5\% of cows with metritis did not have an increased temperature upon diagnosis. Similarly, other studies have indicated that temperature monitoring alone is not an adequate indicator of illness in fresh cows, primarily because a high percentage of "healthy" cows have an elevated temperature following calving (Kristula et al., 2001; Wenz et al., 2011).

Because RT was not measured until parturition, a baseline had not been properly established for postpartum cows as they were enrolled in the study. Therefore, increases in RT during the first days of lactation could not be included in the data analysis. The authors recommend administering the TSRB at dry off to obtain approximately 2 mo of baseline RT and be able to better evaluate temperature changes in the peri- and postpartum period of each milking cow.

Because disease diagnoses were made by dairy personnel, it could be argued that a degree of uncertainty exists in the consistency among employees responsible 
Table 2. Data for $4 \mathrm{~d}$ before diagnosis of cows presenting with an increased reticular temperature (RT) of $>0.8^{\circ} \mathrm{C}$ above their baseline temperature and the presence or absence (i.e., healthy controls) of mastitis, lameness, metritis, or pneumonia

\begin{tabular}{|c|c|c|c|c|c|c|}
\hline \multirow{2}{*}{$\begin{array}{l}\text { Health } \\
\text { event }\end{array}$} & \multicolumn{2}{|c|}{$\begin{array}{l}\mathrm{RT}>0.8^{\circ} \mathrm{C} \\
\text { above baseline }\end{array}$} & \multirow{2}{*}{$\begin{array}{c}\text { Proportion of RT } \\
>0.8^{\circ} \mathrm{C} \text { above } \\
\text { baseline }(\%)\end{array}$} & \multirow{2}{*}{$\begin{array}{l}\text { Odds } \\
\text { ratio }\end{array}$} & \multirow[b]{2}{*}{$P$-value } & \multirow[b]{2}{*}{$95 \% \mathrm{CI}$} \\
\hline & Yes & No & & & & \\
\hline \multicolumn{7}{|l|}{ Mastitis } \\
\hline Present & 73 & 36 & 67 & $6.73^{\mathrm{a}}$ & \multirow{2}{*}{$<0.0001$} & \multirow{2}{*}{$3.55,12.85$} \\
\hline Absent & 25 & 83 & 23 & $\operatorname{Ref}^{1}$ & & \\
\hline \multicolumn{7}{|l|}{ Lameness } \\
\hline Present & 13 & 51 & 20 & 0.83 & \multirow{2}{*}{0.67} & \multirow[t]{2}{*}{$0.33,2.09$} \\
\hline Absent & 15 & 49 & 23 & $\operatorname{Ref}^{1}$ & & \\
\hline \multicolumn{7}{|l|}{ Metritis } \\
\hline Present & 10 & 5 & 67 & 2.20 & \multirow[t]{2}{*}{0.18} & \multirow[t]{2}{*}{$0.60,9.09$} \\
\hline Absent & 30 & 33 & 48 & $\operatorname{Ref}^{1}$ & & \\
\hline \multicolumn{7}{|c|}{ Pneumonia } \\
\hline Present & 10 & 3 & 77 & $7.50^{\mathrm{a}}$ & \multirow[t]{2}{*}{0.047} & \multirow{2}{*}{$1.38,40.59$} \\
\hline Absent & 4 & 9 & 31 & $\operatorname{Ref}^{1}$ & & \\
\hline
\end{tabular}

for classifying cows into the various categories of disease examined in this report. The authors argue, however, that disease diagnosis throughout the study is consistent with industry practices, where farm personnel are responsible for identifying and diagnosing sick cows. It should also be stated that, although dairy personnel did not have access to the RT data during the duration of the study, it is possible those employees responsible for identifying sick animals became more aware of the health status of milking cows following bolus placement. If this were the case, it could be argued that dairy personnel were more aware and identified more sick animals than they would normally. As a result of this potentially increased awareness, the proportion of cows diagnosed with a health event may be higher than it would be under routine circumstances. Also, because health disorders were classified by body system affected and the resulting clinical signs and not by specific etiology, it is very possible that the value of increased core temperature as a predictor of disease caused by a specific agent was not apparent in this study. This could well be the case of lameness as a sign of disease. Future studies should focus on etiological agents and the likelihood of a fever before clinical signs of disease.

Although the normal body temperature of dairy cows is reported to range from 38.0 to $39.4^{\circ} \mathrm{C}$ (Hewitt, 1921; Hicks et al., 2001; Bewley et al., 2008b) variation can occur between cows due to diurnal variations, activity level, estrus, and environmental conditions (Wrenn et al., 1961; Lefcourt et al., 1999; Bewley et al., 2008b; Schutz and Bewley, 2009). Being able to establish a baseline temperature, taking into account diurnal and environmental variations, allows for a more accurate assessment on the individual cow level (Lefcourt et al.,
1999). Not every cow maintains the same core body temperature, making a defined cutoff for disease diagnosis difficult. A cow whose normal body temperature rests in the upper percentile of the normal temperature range, at $39.1^{\circ} \mathrm{C}$, may be completely healthy yet be considered to possess a fever when her temperature is $39.5^{\circ} \mathrm{C}$, potentially receiving unnecessary medical treatment. Conversely, some cows maintain RT on the lower end of the accepted range, at $38.1^{\circ} \mathrm{C}$. At $39.0^{\circ} \mathrm{C}$ these cows would have a fever, but would be considered normal and may not be treated for a disease that they did have, potentially resulting in increased treatment costs later if the producer is using a cutoff point instead of a baseline measurement. Using individual cow baselines to monitor RT removes the cow-to-cow variability and allows producers to manage herd health more efficiently while addressing each animal's status and needs individually.

Although not every cow with elevated body temperature will have a health disorder (Kristula et al., 2001; Wenz et al., 2011), this study indicates that $67 \%$ of them did have an increase in RT $4 \mathrm{~d}$ before the clinical diagnosis of mastitis, hence the importance of continuing this practice on dairy farms. A TSRB, such as the battery-free one used in this study, can be a useful tool to aid dairy producers in monitoring their cows for deviations from the cow's baseline temperature and in the early diagnosis of health events. The bolus used in this study lasts the life of the cow, as it is battery free. Other TSRB may be powered by a battery, however, and may only transmit temperature for the life of the battery. Using a TSRB allows producers to use a relatively noninvasive means of monitoring temperature while removing external manipulating factors, reducing 
the stress on the animals (as restraint is not necessary to measure reticular temperature), and decreasing labor efforts (Hicks et al., 2001; Bewley et al., 2008a). Concerns related with using a TSRB include the initial monetary input required for system installation along with the decrease in RT that occurs when a cow drinks water just before temperature reading (Bewley et al., 2008a).

Once the TSRB has been placed, the producer is able to closely monitor cows that are at high risk for increased body temperature, such as cows in the hospital and fresh pens - as well as cows that are in milking pens, which would not normally be monitored in this way. The benefits of having a TSRB in fresh and hospital cows is apparent, as most operations monitor their fresh cows on a daily basis and a TSRB removes the need for farm personnel to manually measure the rectal temperature of each cow; however, the benefits gained in the milking pens are less obvious. Results from this study indicate that before being diagnosed with pneumonia or mastitis, a cow is likely to have a fever. Examination of these cows at the onset of fever could allow for earlier disease diagnosis and potentially lead to a more timely treatment and quicker recovery and return to the milking system, thus reducing the economic effect of the disease. Although not every cow with elevated body temperature will have a health disorder, the probability that she will is high enough to warrant an examination by farm personnel for other signs of disease. For example, in the case of mastitis, approximately 2 of every 3 cows with a fever that are examined will have mastitis, allowing these 2 cows to receive prompt treatment. We recognize that the relatively low discriminating power of increases in RT compromises the value of TSRB as a diagnostic tool, and that examining every cow with a fever will add labor costs to the operation. These are factors that must be considered when assessing the benefits of including TSRB in the health management program.

We agree that, although the TSRB can be a helpful tool in the management of dairy cow health, dairy personnel should not rely on this tool as a sole method for the identification of sick cows. No single measurement should replace careful observation and husbandry practices that promote early disease identification and prompt and appropriate treatment of ill animals; however, a TSRB could be used in conjunction with daily observations and other diagnostic tools as a way to individually manage animals at risk of developing disease, increasing their chances of remaining in the herd as healthy and productive dairy cows. Associations between RT measured by TSBR and its ability to assist in the early detection of illness among dairy cows should be further investigated to determine if the results of this pilot study in one dairy are consistent in a larger dairy population sample when controlling for potential confounding factors at the animal, herd, and working personnel levels.

\section{CONCLUSIONS}

Temperature monitoring is a useful practice to aid in the early detection of dairy cow diseases. Incorporating a TSRB into the health monitoring program on commercial dairy farms is likely to improve disease detection and overall herd health. Placing the TSRB at dry off would allow an adequate baseline temperature to be established for each cow before calving, enabling dairy personnel to easily monitor changes in body temperature, examining those cows that present an increase in RT. Although not every cow with an increase in temperature from its baseline will be diagnosed with an illness, it is important that cows with an elevated RT are examined. By including a TSRB monitoring system on their facility, producers would be adding one more tool to help maintain herd health - one that will promote close monitoring of individual dairy cows and aid in the prompt identification and treatment of cows that are diagnosed with common production diseases.

\section{REFERENCES}

Aalseth, E. 2005. Fresh cow management: What is important, what does it cost, and what does it return? Pages 1-12 in Proc. Western Dairy Management Conf., Reno, NV.

Akers, R. M., and S. C. Nickerson. 2011. Mastitis and its impact on structure and function in the ruminant mammary gland. J. Mammary Gland Biol. Neoplasia 16:275-289.

Benzaquen, M. E., C. A. Risco, L. F. Archbald, P. Melendez, M. J. Thatcher, and W. W. Thatcher. 2007. Rectal temperature, calving-related factors, and the incidence of puerperal metritis in postpartum dairy cows. J. Dairy Sci. 90:2804-2814.

Bewley, J. M., M. E. Einstein, M. W. Grott, and M. M. Schutz. 2008a. Comparison of reticular and rectal core body temperature in lactating dairy cows. J. Dairy Sci. 91:4661-4672.

Bewley, J. M., M. W. Grott, M. E. Einstein, and M. M. Schutz. 2008b. Impact of intake water temperatures on reticular temperatures of lactating dairy cows. J. Dairy Sci. 91:3880-3887.

Bicalho, R. C., V. S. Machado, and L. S. Caixeta. 2009. Lameness in dairy cattle: A debilitating disease or a disease of debilitated cattle? A cross-sectional study of lameness prevalence and thickness of the digital cushion. J. Dairy Sci. 92:3175-3184.

Burfeind, O., M. A. G. von Keyserlingk, D. M. Weary, D. M. Veira, and W. Heuwieser. 2010. Short communication: Repeatability of measure of rectal temperature in dairy cows. J. Dairy Sci. 93:624-627.

Cha, E., J. A. Hertl, D. Bar, and Y. T. Gröhn. 2010. The cost of different types of lameness in dairy cows calculated by dynamic programming. Prev. Vet. Med. 97:1-8.

Colak, A., B. Polat, Z. Okumus, M. Kaya, L. E. Yanmaz, and A. Hayirli. 2008. Short communication: Early detection of mastitis using infrared thermography in dairy cows. J. Dairy Sci. 91:4244-4248.

Edwards, J. L., and P. R. Tozer. 2004. Using activity and milk yield as predictors of fresh cow disorders. J. Dairy Sci. 87:524-531.

Hewitt, E. A. 1921. A preliminary study of the normal variation in the temperature of cattle. J. Am. Vet. Med. Assoc. 58:544-548. 
Hicks, L. C., W. S. Hicks, R. A. Bucklin, J. K. Shearer, D. R. Bray, P. Soto, and V. Carvalho. 2001. Comparison of methods of measuring deep body temperatures in dairy cows. Pages 432-438 in Livestock Environment VI: Proc. 6th International Symposium, Louisville, KY.

Juarez, S. T., P. H. Robinson, E. J. DePeters, and E. O. Price. 2003. Impact of lameness on behavior and productivity of lactating Holstein cows. Appl. Anim. Behav. Sci. 83:1-14.

Kelton, D. F., K. D. Lissemore, and R. E. Martin. 1998. Recommendations for recording and calculating the incidence of selected clinical diseases of dairy cattle. J. Dairy Sci. 81:2502-2509.

Kristula, M., B. I. Smith, and A. Simeone. 2001. The use of daily postpartum rectal temperatures to select dairy cows for treatment with systemic antibiotics. Bovine Pract. 35:117-125.

LeBlanc, S. J., T. F. Duffield, K. E. Leslie, K. G. Bateman, G. P. Keefe, J. S. Walton, and W. H. Johnson. 2002. Defining and diagnosing postpartum clinical endometritis and its impact of reproductive performance in dairy cows. J. Dairy Sci. 85:2223-2236.

Lefcourt, A. M., J. B. Huntington, R. M. Akers, D. L. Wood, and L. Bitman. 1999. Circadian and ultradian rhythms of body temperature and peripheral concentrations of insulin and nitrogen in lactating dairy cows. Domest. Anim. Endocrinol. 16:41-55.

Melendez, P., J. McHale, J. Bartolome, L. F. Archbald, and G. A. Donovan. 2004. Uterine involution and fertility of Holstein cows subsequent to early postpartum $\mathrm{PGF}_{2 \alpha}$ treatment for acute puerperal metritis. J. Dairy Sci. 87:3238-3246.

Melendez, P., and C. A. Risco. 2005. Management of transition cows to optimize reproductive efficiency in dairy herds. Vet. Clin. North Am. Food Anim. Pract. 21:485-501.
Nakamura, R. M., C. T. Araki, N. L. Clarke, and L. W. G. Kam. 1983. Temperature telemetry studies in dairy cattle in hot climates. Pages 464-469 in National Conference on Agricultural Electronics Applications. Am. Soc. Agric. Eng., Chicago, IL.

Palenik, T., R. Dolezel, J. Kratochvil, S. Cech, J. Zajic, Z. Jan, and M. Vyskocil. 2009. Evaluation of rectal temperature in diagnosis of puerperal metritis in dairy cows. Vet. Med. 54:149-155.

Schutz, M. M., and J. M. Bewley. 2009. Implications in changes in core body temperature. Pages 39-54 in Tri-State Dairy Nutr. Conf. Proc., Columbus, $\mathrm{OH}$.

Sheldon. I. M., G. S. Lewis, S. LeBlanc, and R. O. Gilbert. 2006 Defining postpartum uterine disease in cattle. Theriogenology 65:1516-1530.

Sheldon, I. M., A. N. Rycroft, and C. Zhou. 2004. Association between postpartum pyrexia and uterine bacterial infection in dairy cattle. Vet. Rec. 154:289-293.

Wagner, S. A., D. E. Schimek, and F. C. Cheng. 2008. Body temperature and white blood cell count in postpartum dairy cows. Bovine Pract. 42:18-26.

Wenz, J. R., D. A. Moore, and R. Kasinmanickam. 2011. Factors associated with the rectal temperature of Holstein dairy cows during the first 10 days in milk. J. Dairy Sci. 94:1864-1872.

Wrenn, T. T., J. Bitman, and J. F. Sykes. 1961. Diurnal patterns of bovine body temperature. J. Dairy Sci. 44:2077-2080. 